This item was submitted to Loughborough's Research Repository by the author.

Items in Figshare are protected by copyright, with all rights reserved, unless otherwise indicated.

\title{
Multilayer aperture ring frequency selective surface modelling
}

PLEASE CITE THE PUBLISHED VERSION

PUBLISHER

(C) IEEE

VERSION

VoR (Version of Record)

LICENCE

CC BY-NC-ND 4.0

\section{REPOSITORY RECORD}

Jayawardene, Mohan B.R., R. Dickie, James A. Flint, J.C. Vardaxoglou, R. Cahill, H.S. Gamble, V.F. Fusco, and N. Grant. 2019. "Multilayer Aperture Ring Frequency Selective Surface Modelling". figshare. https://hdl.handle.net/2134/6290. 
This item was submitted to Loughborough's Institutional Repository (https://dspace.lboro.ac.uk/) by the author and is made available under the following Creative Commons Licence conditions.

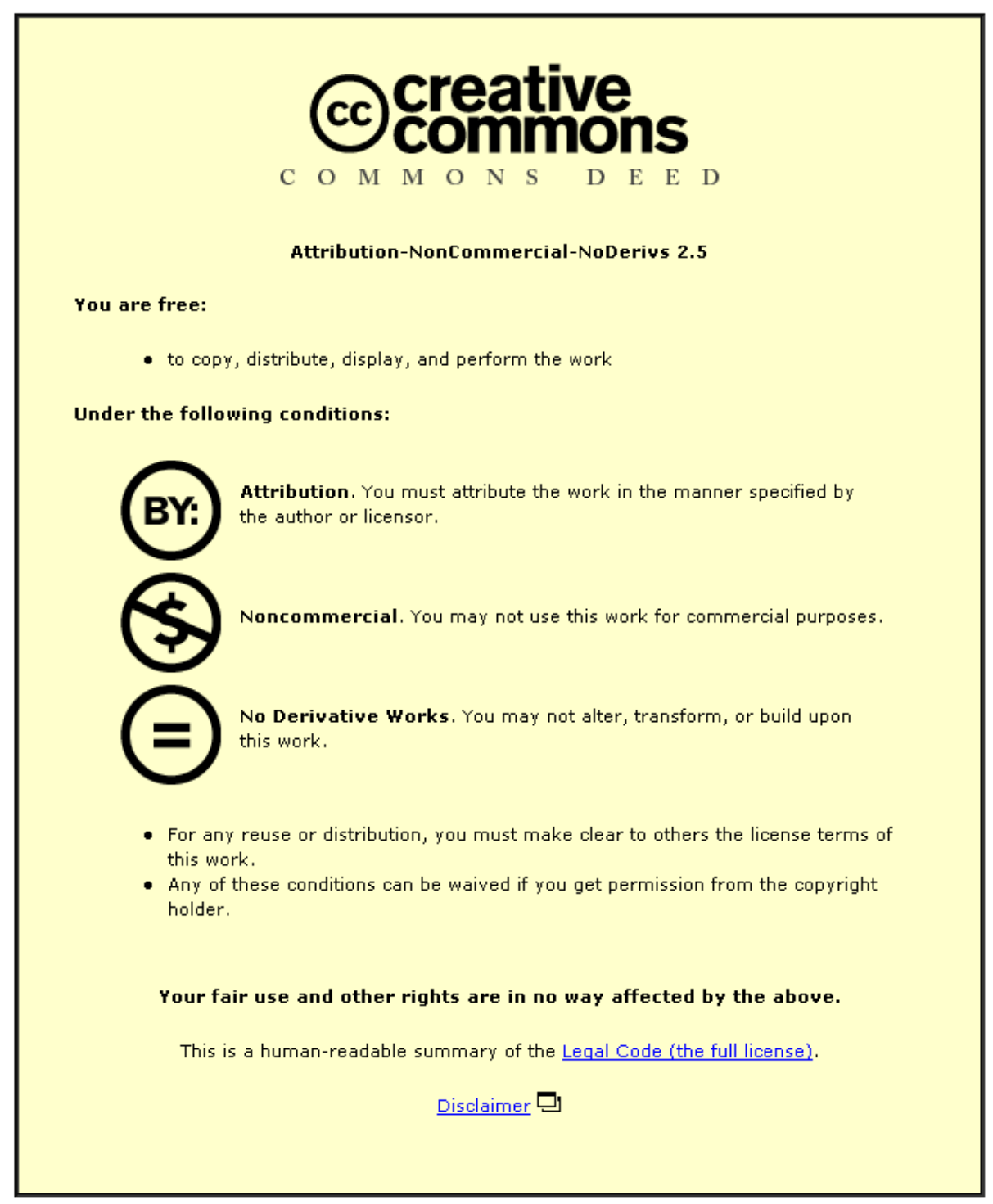

For the full text of this licence, please go to: http://creativecommons.org/licenses/by-nc-nd/2.5/ 


\title{
Multilayer Aperture Ring Frequency Selective Surface Modelling
}

\author{
M Jayawardene ${ }^{(1)}$, R Dickie $^{(2)}$, J A Flint ${ }^{(1)}$, J C Vardaxoglou ${ }^{(1) *}$, \\ R Cahill ${ }^{(2)}$, H S Gamble ${ }^{(2)}$, V F Fusco ${ }^{(2)}$, N Grant ${ }^{(3)}$ \\ (i) Centre for Mobile Communications Research (CMCR) \\ Department of Electronic and Electrical Engineering, Loughborough University, \\ Loughborough, Leicestershire LE11 3TU \\ Email: M.Jayawardene@boro.ac.uk
}

(2) The Institute of Electronics, Communications and Information Technology (ECIT) Queen's University of Belfast, Northern Ireland Science Park, Queen's Road Queen's Island, Belfast BT3 9DT Email:r.cahill@qub.ac.uk

\author{
(3) EADS ASTRIUM, Directorate of Earth Observation and Science, \\ Anchorage Road, Portsmouth PO3 5PU, Hampshire, UK \\ Email:norman.grant@eads.astrium.net
}

\begin{abstract}
This paper describes the design of a low loss quasi-optical beam splitter, which is required to provide efficient diplexing of the bands $316.5-325.5 \mathrm{GHz}$ and $349.5-358.5 \mathrm{GHz}$ with at least $20 \mathrm{~dB}$ of isolation. To minimise the filter insertion loss, a Frequency Selective Surfaces (FSS) that consists of freestanding resonant shorted ring elements is proposed. In addition, to achieve the stringent isolation a two layer FSS structure is required. Two commercial electromagnetic modelling tools, a time domain Finite Integral Method (FIT) and a Finite Element Method (FEM) solver are used to obtain the specified transmission response. The FIT solver was used to generate fast design information at normal incidence while the FEM was only used to obtain the final design of the FSS at $45^{\circ}$, due to its substantially increased run times.
\end{abstract}

\section{Introduction}

For space borme instruments, FSS are usually constructed by printing arrays of selfresonant periodic elements on the surface of thin $\mathrm{SiO}_{2}$ wafers [1]. This material is suitable for use in space hardware and has a low loss tangent [2]. Although printed FSS have been employed in a large number of experimental radiometers $[2,3]$, there are two major technological challenges, which must be addressed to achieve the performance requirements demanded by future sounding systems. Firstly, a reduction of the insertion loss is required, because for high-Q multilayer FSS designs around $350 \mathrm{GHz}$, this has been shown to be in excess of $2 \mathrm{~dB}$ [1]. Secondly, a construction technique must be developed to overcome the structural limitations on the use of this type of diplexer at very high frequencies, because for filter designs working above $500 \mathrm{GHz}$ the substrate would be too thin and fragile to survive typical launch forces. In both cases the performance limitation factor is a consequence of the dielectric material that is used to support the printed self-resonant elements. 
The merits of freestanding FSS designs and manufacturing techniques at millimetre wavelengths have been previously reported by the authors in $[2,3,4,5]$. For this work, the design objective was to separate the bands $316.5-325.5 \mathrm{GHz}$ and $349.5-358.5 \mathrm{GHz}$ with $<1.5 \mathrm{~dB}$ loss and $>20 \mathrm{~dB}$ isolation in either the TE or TM planes at $45^{\circ}$. This is the performance that has been specified for the band $\mathrm{C}$ single side band filter for the European Space Agency MARSCHALS multi-channel limbsounding instrument [3]

In this paper a new element design is described which has the potential to increase the structural stability of the freestanding dichroic screens, by replacing the dipole slots $[2,5]$ in the periodic arrays with shorted rings [6,7]. This increases the surface area of metal between the elements by $28 \%$ (see Figure 1) which is structurally more desirable, and furthermore this concept offers the possibility of providing dual polarisation and dual band filtering simply by introducing a second suitably orientated spilt ring in the unit cell [8].

Two commercially available modelling packages were used to simulate the aperture FSS array. Though each package in their merit has desirable features for FSS array modelling, it is a compromise between the capability of the package, simulation time and the reliability of the results. In this study several parameters of the unit cell were changed in order to quantify and optimise the performance of the filter. By modelling the unit cell with zero thickness Perfect Electric Conductor (PEC) one can demonstrate almost zero mismatch loss for this design. Furthermore, the effects of increasing the slot depth shows an increase in the roll-off rate and incremental aperture width increases show improved bandwidth whilst changing the conductivity from PEC to copper demonstrates the effects of insertion loss in the passband

\section{Simulating the shorted ring array using commercial software}

A unit cell consisting of the shorted ring is modelled in CST's Microwave Studio (MWS) time domain solver. For normal incidence, symmetry boundary conditions were chosen to excite a TM incident wave as shown in Figure 1. However, this is only valid for normal incidence, as the image theory will not hold for oblique angles. The geometry is efficiently meshed using the $\mathrm{PBA}^{T M}$ meshing technique inherent to the package unlike the classical staircase mesh used in time domain solvers. The mesh parameters were optimised to produce a convergent response in the frequency domain. A frequency sweep from $200 \mathrm{GHz}-400 \mathrm{GHz}$ for the geometry shown in Figure 1 on a $2 \mathrm{GHz}$ Xeon dual processor machine in the time domain typically takes 10 minutes to run.

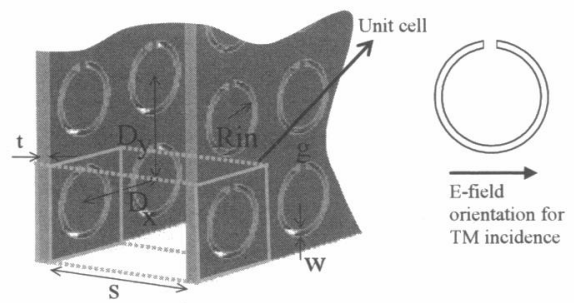

Figure 1: Free-standing resonant shorted aperture ring 2-layer FSS;

Rin $=154.0 \mu \mathrm{m}, W=15 \mu \mathrm{m}, D_{x}=680 \mu \mathrm{m}, D_{y}=487 \mu \mathrm{m}, S=320 \mu \mathrm{m}, g=30 \mu \mathrm{m}, t=10 \mu \mathrm{m}$ 


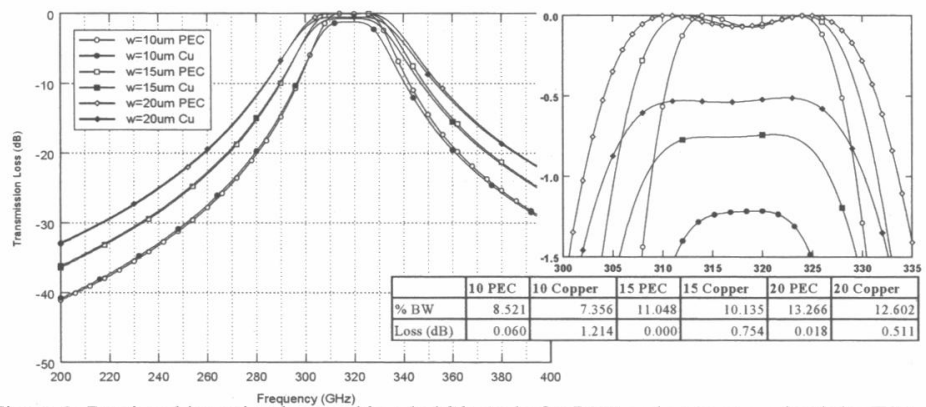

Figure 2: Passband insertion loss and bandwidth study for PEC and copper conductivity FSS, with aperture width $w$, modelled at normal incidence using the FIT method

Figure 2 shows the variation in the roll-off rate, bandwidth and the pass-band loss when the width of the shorted ring is increased whilst maintaining a slot thickness of $10 \mu \mathrm{m}$. By increasing the slot width by $10 \mu \mathrm{m}$ and keeping the conductivity to be PEC, the mismatch loss remains around $0.1 \mathrm{~dB}$. However, the roll-off rate becomes shallower and the bandwidth is increased. As the conductivity of the array is now changed from a PEC to copper, the effects of the insertion loss is clearly seen. As an example for an aperture width of $10 \mu \mathrm{m}$, the insertion loss increases to $1.2 \mathrm{~dB}$ for an aperture width of $10 \mu \mathrm{m}$. As the width of the aperture is increased to $20 \mu \mathrm{m}$, this loss is reduced to 0.5 $\mathrm{dB}$. However there is a slight reduction in the roll-off.

Predictions at $\mathrm{TM} 45^{\circ}$ incidence for the same structure were computed using the fullwave 3D Finite Element Method (FEM) software, HFSS ${ }^{\mathrm{TM}}$. Meshing was carried out adaptively at $500 \mathrm{GHz}$ until the field errors were reduced to a prescribed value and then non-adaptively over the swept frequencies. On a $2 \mathrm{GHz}$ Pentium dual processor PC, adaptive and non-adaptive solutions typically take 30 minutes and 15 minutes respectively to solve for the fields in the unit cell at each frequency. The model can take account of aperture thickness and surface conductivity, these effects are important as the former increases the filter roll-off and the latter introduces insertion losses, as shown in Figure 3.

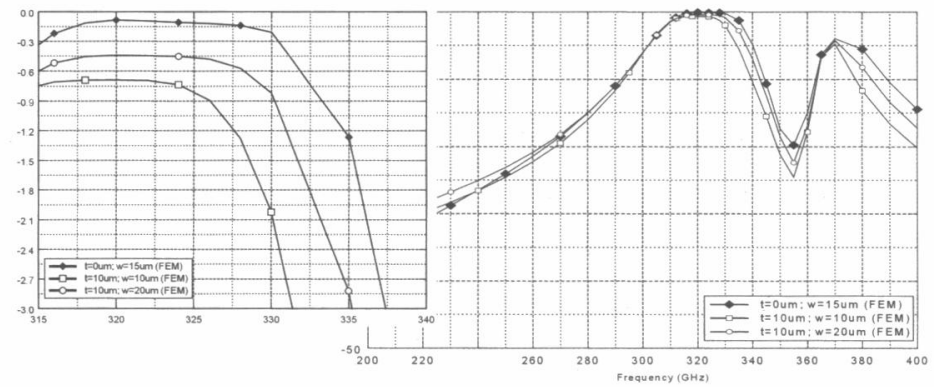

Figure 3: Passband insertion loss and bandwidth study for PEC and copper conductivity FSS, with aperture width $w$ and slot depth, modelled at $45^{\circ} \mathrm{TM}$ incidence using the FEM method 
For the PEC FSS surface, the insertion loss at $321 \mathrm{GHz}$ is $0.15 \mathrm{~dB}$ and this increases to $0.5 \mathrm{~dB}$ when the PEC is changed to copper conductivity. These values show good correlation with the normal incidence plots shown in Figure 2. Also, the insertion loss decreases when the aperture width (w) is increased from $10 \mu \mathrm{m}$ to $20 \mu \mathrm{m}$, while increasing the bandwidth and reducing the $\mathrm{Q}$ of the filter. Although the results show the similarities in insertion loss and bandwidth effects between the normal and oblique incidence predictions, there are significant differences in the frequency of the rejection bands.

\section{Conclusions}

In this paper it has been shown that shorted aperture ring elements can provide the insertion loss improvement and image band rejection required for future airborne passive radiometers. These elements have potentially improved mechanical characteristics due to the additional metal which separates the slots. The effects of changing the aperture width and the thickness of the FSS on the filter roll-off rate, bandwidth and passband insertion loss have been established using two commercial electromagnetic modelling packages. Similarities between the passband predictions has shown that the FIT method can be used to give fast design information on the insertion loss and bandwidths, which can then be optimised by the more computationally intensive FEM method at oblique incidence.

\section{Acknowledgements}

The authors gratefully acknowledge financial support from the UK Engineering and Physical Sciences Research Council under grant GR/S13828 FSS arrays. The authors would like to acknowledge the support of CST, Ansoft UK and their respective technical support teams.

\section{References.}

[1] R. J. Martin and D. H. Martin, "Quasi-optical antennas for radiometric remote sensing," IEE Electron. \& Comm. Eng. J, 8, pp. 37-48, 1996.

[2] R. Dickie, R. Cahill, V. F. Fusco, H. S. Gamble, B. Moyna, P. Huggard, N. Grant and C. Philpot, "Micromachined $300 \mathrm{GHz}$ High Q resonant slot frequency selective surface filter", Proc. IEE Microwaves Antennas and Propagation, 151, (1), pp. 31-36, 2004.

[3] R. Dickie, R. Cahill, H.S. Gamble, V.F. Fusco, N. Grant and C. Philpot, "Manufacture and performance of multilayer frequency selective surface mesh filters for submillimeter wave applications", $27^{\text {th }}$ ESA Antenna workshop on innovative periodic antennas: electromagnetic bandgap, left-handed materials, fractal and frequency selective surfaces, Spain, pp. 353-360, 2004.

[4] R. Cahill, J. C. Vardaxoglou and M. Jayawardene, "Two Layer mm-Wave FSS of linear slot elements with low insertion loss", Proc. IEE Microwaves Antennas and Propagation, $148,(6)$, pp. 410-412, 2001.

[ 5] R. Dickie, R. Cahill, H.S. Gamble, V.F. Fusco, N. Grant and A.G. Schuchinsky, "Spatial demultiplexing in the sub-mm wave band using multilayer free-standing frequency selective surfaces," Accepted IEEE Trans. Antennas and Propag., June 2004.

[6] A.D. Chuprin, E.A. Parker, J.C. Batchelor, "Resonant Frequencies of Open and Closed Loop FSS Arrays", IEE Electronics Letters, 36, No.19, pp 1601-1603

[7] N. Misran, R. Cahill, and V. F. Fusco, Concentric split ring element for reflectarray antennas", IEE Electron. Lett, 39, (25), pp.1776-1777, 2003

[8] M Jayawardene, R Dickie JA Flint, JC Vardaxoglou, R Cahill, HS Gamble, VF Fusco and N Grant, "Multilayer split ring frequency selective surface for millimeter wave applications," In 13 Journees Internationales de Nice sur les Antennes (JINA2004), Nice France, 8-10 November 2004, pp. 136-137. 